\title{
Additional diagnostic role of MRI spectroscopy, diffusion and susceptibility imaging in differentiation of CPA masses: our experience with emphasis on schwannomas and meningiomas
}

\author{
Marwa Khaled ${ }^{1}$, Khaled Moghazy ${ }^{1}$, Waleed Elsaadany ${ }^{2}$ and Lamya Eissa ${ }^{1 *}$
}

\begin{abstract}
Background: CPA masses are uncommon lesions and usually have quite distinctive imaging features. Still, diagnosis can be challenging in some cases, carrying a significant impact on the choice of treatment and surgical approach. The purpose of this study was to validate the usefulness of MRI spectroscopy, diffusion, and susceptibility in the characterization of CPA masses with the emphasis on the two commonest lesions: schwannomas and meningiomas.

Results: The study included a total of 27 cases: schwannomas $(n=12)$, meningiomas $(n=7)$, epidermoid cysts $(n=$ 2), two chondrosarcomas $(n=2)$, arachnoid cyst $(n=1)$, glomus tumor $(n=1)$, a meningeal metastasis $(n=1)$, and an endolymphatic sac tumor $(n=1)$. DWl revealed: eight lesions showed low ADC $\left(<1 \times 10^{-3} \mathrm{~mm}^{2} / \mathrm{s}\right), 15$ lesions with intermediate ADC values $\left(1-1.8 \times 10^{-3} \mathrm{~mm}^{2} / \mathrm{s}\right)$, and 4 lesions had high ADC $\left(>1.8 \times 10^{-3} \mathrm{~mm}^{2} / \mathrm{s}\right.$.) Meningiomas showed low to intermediate ADC values while schwannomas showed intermediate to high ADC values. A cut-off ADC value of $\left(1 \times 10^{-3} \mathrm{~mm}^{2} / \mathrm{s}\right)$ is statistically significant in the differentiation of meningioma from schwannoma. A myoinositol peak was in all 12 schwannomas and single meningioma while 6 meningiomas displayed alanine peak, with a very good statistical significance. Remaining lesions revealed non-specific spectra. SWI made in 18 lesions revealed signal voids in three schwannomas and glomus.

Conclusions: Though MRI features of CPA masses are distinctive in most clinical settings; MRI spectroscopy, diffusion, and susceptibility can provide highly informative additional data in problematic cases. An intermediate to high ADC value plus myoinositol peak and signal voids of micro-bleeds are highly suggestive of schwannomas. This is in contrary to meningiomas displaying low to intermediate ADC and an alanine peak with no micro-bleeds. The less common lesions revealed non-specific data.
\end{abstract}

Keywords: Spectroscopy, Susceptibility, Diffusion, Schwannoma, Meningioma

\footnotetext{
* Correspondence: lamya.eissa@gmail.com

'Department of Diagnostic and Interventional Radiology, Alexandria Faculty

of Medicine, Alexandria 21131, Egypt

Full list of author information is available at the end of the article
}

\section{Springer Open}

(0) The Author(s). 2020 Open Access This article is licensed under a Creative Commons Attribution 4.0 International License, which permits use, sharing, adaptation, distribution and reproduction in any medium or format, as long as you give appropriate credit to the original author(s) and the source, provide a link to the Creative Commons licence, and indicate if changes were made. The images or other third party material in this article are included in the article's Creative Commons licence, unless indicated otherwise in a credit line to the material. If material is not included in the article's Creative Commons licence and your intended use is not permitted by statutory regulation or exceeds the permitted use, you will need to obtain permission directly from the copyright holder. To view a copy of this licence, visit http://creativecommons.org/licenses/by/4.0/. 


\section{Background}

CPA tumors represent $5-10 \%$ of all intracranial tumors in adults and $1 \%$ of intracranial tumors in pediatrics [16]. They combine diverse pathologies, with extra and intra-axial localization of lesions [7-9]. Extra-axial lesions are more common and include vestibular schwannomas, meningiomas, and epidermoid cysts that represent the three most common masses of the CPA. Other extra-axial lesions include arachnoid cysts, fascial nerve, and trigeminal schwannomas. Also, a number of intra-axial lesions exist, though they are rare in incidence, and usually arise as the pedunculated brain stem or intraventricular masses [10, 11].

MRI is considered the imaging modality of choice for evaluating CPA masses owing to its excellent soft-tissue contrast-resolution, multi-planar imaging capability, and absence of beam-hardening artifact, the latest is hindering diagnostic capability of CT due to air-bone interferences $[12,13]$. Usually, a conventional MRI examination can be enough to establish an accurate diagnosis. However, there are several ambiguous cases, where MR advanced techniques can provide additional help [12, 13].

The "CISS" or the three-dimensional constructive interference in steady state is a refocused steady-state gradientecho MRI sequence, which enhances the fluid signal with prolonged T2 relaxation and consequent high sensitivity in the detection of small CPA masses, where they appear as filling defects outlined by CSF [14-17].

Diffusion-weighted MRI is a non-invasive method that measures the molecular diffusion and Brownian motion of water protons. It is largely used in the evaluation of intracranial and head and neck masses, where differentiation between cellularity can give information about the pathology of the mass. An ADC value is calculated and shows an inverse correlation with tumor cellularity: Hypercellular intracranial tumors exhibit low ADC values while hypocellular tumors exhibit high ADC values [18-21].

Susceptibility-weighted imaging (SWI) is a technique that utilizes the magnetic property to create useful image contrast. It uses a gradient echo sequence to combine T2*-weighted "magnitude" image with a filtered "phase" image. This combination is made to enhance susceptibility-induced contrast between tissues, and thus can show blooming in tiny blood products or early tiny calcifications [22, 23].

Perfusion-weighed imaging (PWI) is a method that provides information on cerebral physiology at the capillary bed level (microvasculature). The T2* signal "loss" is produced as a paramagnetic agent (e.g., Gadopentetate dimeglumine) passes through the cerebrovascular system because of local magnetic susceptibility. Thus, this technique can differentiate hypovascular from hypervascular masses [24-26].
MR spectroscopy (MRS) is considered a non-invasive means for characterization of the tissues according to the phenomenon known as chemical shift, where the MR frequency spectrum is received by nuclei resonating at different frequencies [26-30]. Spectroscopy is largely used in neurological imaging evaluation for both local and diffuse disease. Regarding the CPA masses, MRS can be difficult to be performed because of the adjacent skull and bone artifacts making this technique used mainly in large lesions [31-33]. MR spectroscopy has been largely used in the characterization of multiple intra- and extra-axial masses of the neuraxis. For intraaxial lesions, grading of gliomas was made according to variable NAA and choline metabolites, while extra-axial masses show more variable metabolites [34-36].

CPA schwannomas and meningiomas are the most common CPA mass lesions and are usually easily differentiated by conventional methods using a number of signs, including signal, enhancement pattern, dural tails, obtuse angle, and intracanalicular extension +/- flaring. However, atypical lesions can exit due to markedly variegated histopathological types [35, 36].

The cranial neuro-advanced MRI techniques can be also applied in the evaluation of CPA masses despite the challenge of multiple air, bone, and fluid interfaces. State-of-art MRI machines applying high spatial resolution with the use of dedicated multi-channel coils can overcome this anatomical challenge [37-39].. The aim of this work was to evaluate the usefulness of additional MRI techniques diffusion, SWI, and spectroscopy in the characterization of CPA masses. A special emphasis was made for the two commonest schwannomas and meningiomas.

\section{Methods}

\section{Study design and patient selection}

The protocol of our prospective study had approval made by the Institutional Review Board (IRB) of our university hospital. Patient approval and informed consent were acquired from all patients in a written form (by the patient or a relative). (A) Inclusion criteria included the following: only the adult population ( $\geq 18$ years old) with: (a) questionable retro-cochlear pathology as referred to our radiology department by otolaryngology or neuro-surgery physician or (b) with incidental finding of CPA nonvascular mass by routine imaging (CT or MRI). Exclusion criteria included (a) pediatric population ( $<18$ years), (b) non-mass lesions (e.g., vascular loops), and primarily vascular lesions (e.g., aneurysms) were excluded.

\section{Clinical evaluation}

All patients included in the study were subjected to [1] full history taking and thorough clinical examination, [2] laboratory investigations namely serum creatinine level, 
then creatinine clearance was calculated, using "Cockcroft-Gault Equation", [3] the medical ethics were considered and the study protocol was already approved by the Institutional Review Board (IRB).

\section{MRI imaging evaluation}

A) All patients are examined on a 1.5 Tesla closed MRI Scanner (Phillips Achieva, Phillips medical system, Best, The Netherlands). This is a 32-channel closed machine using a standard imaging head coil. Conventional MRI sequences included T2WI (axial across whole brain), T2WI (axial and coronal across CPA), T1WI pre- and post-contrast: axial and coronal across CPA, and axial FLAIR across whole brain. T2WI (TR $4045 \mathrm{~ms}$, TE $110 \mathrm{~ms}$, FOV $23 \times$ $18.5 \mathrm{~cm}$, flip angle $90^{\circ}$, slice thickness $5 \mathrm{~mm}$, and inter-slice gap $1 \mathrm{~mm}$ ), thin cut T2WI (TR $3360 \mathrm{~ms}$, TE $81 \mathrm{~ms}$, FOV $17 \times 15 \mathrm{~cm}$, flip angle $90^{\circ}$, slice thickness $3 \mathrm{~mm}$, and inter-slice gap $0.3 \mathrm{~mm}$ ), thin cuts T1WI (TR $500 \mathrm{~ms}$, TE $10 \mathrm{~ms}$, FOV $17 \times 15 \mathrm{~cm}$, flip angle $90^{\circ}$, slice thickness $3 \mathrm{~mm}$ and inter-slice gap $0.3 \mathrm{~mm}$ ), FLAIR (TR 10,000 ms, TE $140 \mathrm{~ms}$, FOV $23 \times 23 \mathrm{~cm}$, flip angle $90^{\circ}$, slice thickness 5 $\mathrm{mm}$ and inter-slice gap $1 \mathrm{~mm}$ ). CISS (TR 1055, TE 235 , FOV $13 \times 13 \mathrm{~cm}$, flip angle $90^{\circ}$, slice thickness $1 \mathrm{~mm}$, and inter-slice gap $0.3 \mathrm{~mm}$ ).

B) DWI (TR $2095 \mathrm{~ms}$, TE $90 \mathrm{~ms}$, FOV $23 \times 18.5 \mathrm{~cm}$, flip angle $90^{\circ}$, slice thickness $5 \mathrm{~mm}$ and inter-slice gap $1 \mathrm{~mm}$ ). The diffusion-sensitizing gradients were applied three b-factors and are obtained including 0,500 , and $1000 \mathrm{~s} / \mathrm{mm}^{2}$ in the axial plane. ADC maps were automatically reconstructed for all DW images and used for the measurement of ADC values in regions of interest (ROIs) at the center of the lesions. The ADC values were expressed in $x$ $10^{-3} \mathrm{~mm}^{2} / \mathrm{s}$.

C) For SWI: These parameters used are TR $52 \mathrm{~ms}$, TE $12 \mathrm{~ms}$, FOV $23 \times 23$, flip angle $20^{\circ}$, slice thickness $5 \mathrm{~mm}$ and inter-slice gap $1 \mathrm{~mm}$ ). Two phases are generated: phase and magnitude images. This is followed by a filtering technique of the two images. The SWI is selectively done in lesions revealed by conventional criteria as schwannoma or meningioma.

D) For MRS: A single-voxel 1H-MR spectroscopy was performed. A volume of interest (VOI) between 1 $\mathrm{cm}^{3}$ and $8 \mathrm{~cm}^{3}$ was placed on the lesion where the largest possible voxel was positioned within the enhancing solid part of the brain lesion with minimal contamination from the surrounding tissue. Two spectra were acquired from the same VOI for every case at [1] short TE (2000/31) (TR/TE) [2]. Long TE (2000/144). Spectrum analysis was performed using software spectroscopy within the MR scanner. The intensities of the data points of the spectrum between 0 and $4.00 \mathrm{ppm}$ were selected and used as input for the normalization and statistical analysis. MR spectroscopy will be applied for solid noncystic lesions $>1 \mathrm{~cm}$ in size.

E) For MR perfusion (TR $2300 \mathrm{~ms}$, TE $40 \mathrm{~ms}$, FOV 30 $\times 30$, flip angle $75^{\circ}$, slice thickness $3.5 \mathrm{~mm}$ and slice gap $1 \mathrm{~mm}$ ). PWI was performed with a firstpass contrast-enhanced $\mathrm{T} 2 * \mathrm{~W}$ single-shot gradientecho sequence using a rapid bolus of $0.1 \mathrm{mmol} / \mathrm{kg}$ of MRI contrast material (Gadolinium (Gadopentetate dimeglumine with a dose of $0.1 \mathrm{mmol} / \mathrm{kg}$ ) followed by $20 \mathrm{ml}$ saline flush.). CBV maps, colorcoded perfusion maps as well as rCBV values and time-intensity curves were analyzed. The PWI was made only when feasible. It is made as an auxiliary technique and not primarily included in our research target.

\section{Image analysis}

The images were interpreted by two experienced senior and junior "head and neck" radiologists, with 25 years and 15 years of experience, respectively. The images are analyzed as detailed below:

On conventional MRI sequence, the lesion was analyzed according to (a) T1 signal as compared to the brain parenchyma (T1 hypo or iso), (b) T2 signal intensity (hypo, iso, hyperintense compared to brain parenchyma or bright=CSF signal), (c) nulling on FLAIR, (d) enhancement pattern graded as (hyper, hypo, or moderate as compared to enhanced muscles) and described as homogenous or heterogeneous), (e) the presence of cystic changes, (f) its extension the IAC $+/$ - flaring, (g) the presence of dural tail, (h) the presence extra-cranial extension.

A) On DWI images: the lesion was analyzed according to whether it is hyper, iso, or hypointense to the brain parenchyma, and the ADC are measured by $\mathrm{ROI}$ of the solid non-necrotic portion. ADC value was categorized to less than $1 \times 10-{ }^{3} / \mathrm{cm}^{2}$, from 1 to $1.7 \times 10^{-3} / \mathrm{cm}^{2}$ and more than $1.8 \times 10^{3} / \mathrm{cm}^{2}$.

B) On SWI, the lesions were analyzed according to the presence of intralesional signal voids that signify intralesional hemorrhage or calcifications. The findings are evaluated in filtered images and MIP images to differentiate calcifications and hemorrhages. The filtered phase images are examined on this right-handed machine as follows: 
The hemorrhages appear low signal while calcification appears of opposite signal intensity (high signal).

C) On CISS, the lesions were analyzed according to their relation with the vestibule-cochlear nerve whether (a) encasing, (b) abutting, (c) displacing, or (d) none.

D) On MRS, the lesions were mainly analyzed according to the presence of different metabolites.

E) On MR perfusion: the lesions were categorized as hypo or hyperperfused on qualitative analyses of generated maps, measuring relative perfusion of the lesion as compared to normal temporal lobe parenchyma (Relative Tumoral blood volume).

\section{Statistical analysis}

Data were fed to the computer and analyzed using IBM SPSS software package version 20. The distributions of quantitative variables (ADC-values) were tested for normality using the Kolmogorov-Smirnov test. For abnormally distributed data, Kruskal-Wallis test was used to compare between different groups and Mann-Whitney test was assessed for pair-wise comparisons. The receiver operating characteristic curve (ROC) was plotted to analyze a recommended cutoff, the area under the ROC curve denotes the diagnostic performance of the test. Area more than $50 \%$ gives acceptable performance and area about $100 \%$ is the best performance for the test. The significance of the obtained results was judged at the $5 \%$ level.

\section{Results}

This study included 27 cases with CPA masses that were recommended for imaging and/or planned for surgical resection of the tumor during 16 months of prospective work, which started from 1-7-2018 until 30-11-2019. This small sample size is because CAP masses are uncommon. The study included 14 males and 13 females with no sex predominance. The age of studied patients ranged with an age range from 20 to 60 years (with a mean of 40 years) (Table 1).

Table 1 Distribution of the studied cases according to their diagnosis $(n=27)$

\begin{tabular}{lll}
\hline Diagnosis & No. & $\%$ \\
\hline Schwannoma & 12 & 44.4 \\
Meningioma & 7 & 25.9 \\
Epidermoid & 2 & 7.4 \\
Arachnoid cyst & 1 & 3.7 \\
Chondrosarcoma & 2 & 7.4 \\
Glomus & 1 & 3.7 \\
Meningeal metastasis & 1 & 3.7 \\
Endolymphatic sac tumor & 1 & 3.7 \\
\hline
\end{tabular}

The most common presenting symptom in our study was sensorineural hearing loss (55.5\%), followed by headache $(29.6 \%)$, then tinnitus $(7.4 \%)$, then neuralgia (3.7\%), and facial palsy (3.7\%) (Table 2).

All patients had conventional MRI techniques made for them including T1, T2, FLAIR, thin cuts T1 and T2. Also, CISS and DWI were made in all cases. SWI was made in 18 patients (being reserved only for meningiomas and schwannomas). Perfusion (PWI) was made in (made when only feasible and only auxiliary; not a primary technique in our research). MR spectroscopy was made selectively for a total of 22 cases: The twelve schwannomas, the seven meningiomas, the glomus lesion, chondrosarcoma, and endolymphatic sac tumor (thus leaving three cystic lesions, two lesions $<1 \mathrm{~cm}$ ).

Out of our 27 patients, $12(44.4 \%)$ were diagnosed as schwannomas: vestibular schwannomas $(n=10)$, trigeminal schwannoma $(n=1)$, and facial schwannoma $(n=1)$ \{two of the ten vestibular schwannomas were part of NF2-neurofibromatosis type II\}, seven (25.9\%) were meningiomas, epidermoid cysts $(n=2)$ and two chondrosarcomas $(7.4 \%$ for each, one arachnoid cyst $(n=1)$, glomus tumor $(n=1)$, meningeal metastasis in leukemia $(n=1)$, and an endolymphatic sac tumor $(n=1)$.

All 27 lesions were T1 hypo-to-isointense (apart from hyperintense foci in endolymphatic sac tumor). Seventeen lesions were T2 hyperintense: schwannomas $(n=$ $9)$, meningiomas $(n=6)$, endolymphatic sac tumor $(n=$ $1)$, and glomus tumor $(n=1)$. Seven lesions were bright on T2WI: schwannomas $(n=2)$, epidermoid cyst $(n=$ $2)$, chondrosarcoma $(n=2)$, arachnoid cyst $(n=1)$. Two lesions were T2 iso-intense: schwannomas $(n=1)$ and a meningioma $(n=1)$. A single meningeal metastasis 6 $\mathrm{mm}$ lesion was not appreciated neither on T1WI nor T2W1 (only in post-GAD).

Nineteen lesions were hyper-enhancing: all the seven meningiomas $(n=7)$, schwannomas $(n=9)$, chondrosarcoma $(n=1)$, glomus tumor $(n=1)$, and the endolymphatic sac tumor $(n=1)$. Three showed moderate enhancement: a schwannoma $(n=1)$ and chondrosarcoma $(n=1)$ and meningeal metastasis. A single schwannoma showed hypo-enhancement. Also, a single schwannoma showed rim enhancement. Seven lesions showed cystic changes in T2 and post-GAD images:

Table 2 Distribution of the studied cases according to their complaints $(n=27)$

\begin{tabular}{lll}
\hline Complaint & No. & $\%$ \\
\hline Sensorineural hearing loss & 15 & 55.5 \\
Headache & 8 & 29.6 \\
Tinnitus & 2 & 7.4 \\
Neuralgia & 1 & 3.7 \\
Facial palsy & 1 & 3.7 \\
\hline
\end{tabular}


schwannomas $(n=5)$, chondrosarcoma $(n=1)$, and endolymphatic sac tumor $(n=1)$. None of the meningiomas showed cystic changes. The three cystic lesions (two epidermoid and arachnoid cysts) showed nonenhancement.

Seventeen cases showed extension into the IAC: schwannomas $(n=10)$, meningiomas $(n=5)$, chondrosarcoma $(n=1)$, and endolymphatic sac tumor $(n=1)$. Eleven lesions showed flaring of the IAC: all vestibular schwannomas $(n=10)$ and endolymphatic sac tumor $(n=$ $1)$. Eleven cases showed "dural tail": all the seven meningiomas $(n=7)$, schwannomas $(n=3)$, and chondrosarcoma $(n=1)$. Four lesions showed extra-cranial extension: meningiomas $(n=2)$, chondrosarcoma $(n=1)$, and glomus tumor $(n=1)$. Nulling on FLAIR was seen only in the single case of an arachnoid cyst (Table 3).

SWI was done for eighteen patients $(n=18)$, six of them showed "signal voids" within the lesion: four schwannomas $(n=4)$, glomus tumor $(n=1)$, and endolymphatic sac tumor $(n=1)$. None of the meningiomas and remaining lesions showed any signal void.

Out of a total of 27 patients, fourteen lesions were hyperintense, nine were iso-intense, and four were hypointense on DWI. Eight lesions had low/restricted ADC values $<1 \times 10^{-3} \mathrm{~mm}^{2} / \mathrm{s}$, fifteen lesions had intermediate ADC values between 1 and $1.8 \times 10^{-3} \mathrm{~mm}^{2} / \mathrm{s}$ and four lesions had high ADC of $>1.8 \times 10^{-3} \mathrm{~mm}^{2} / \mathrm{s}$ (refer to Fig. 1 showing chart representative of different ADC values among different pathologies).

Out of seven meningiomas: four had ADC values less than $1 \times 10^{-3} \mathrm{~mm}^{2} / \mathrm{s}$ and three meningiomas had ADC values between 1 and $1.7 \times 10^{-3} \mathrm{~mm}^{2} / \mathrm{s}$. Ten schwannomas had ADC values between 1 and $1.7 \times 10^{-3} \mathrm{~mm}^{2} / \mathrm{s}$ (nine vestibular and one facial), one VS ADC value less than $1 \times 10^{-3} \mathrm{~mm}^{2} / \mathrm{s}$ ), while the trigeminal schwannoma had high ADC value more than $1.7 \times 10^{-3} \mathrm{~mm}^{2} / \mathrm{s}$. The two epidermoid cysts as expected showed restricted ADC values $<1 \times 10^{-3} \mathrm{~mm}^{2} / \mathrm{s}$. The arachnoid cyst had a high ADC value of $3 \times 10^{-3} \mathrm{~mm}^{2} / \mathrm{s}$. The single metastasis was hyperintense on DWI and had ADC value $0.5 \times$ $10^{-3} \mathrm{~mm}^{2} / \mathrm{s}$. The one chondrosarcoma had a high ADC value of $2 \times 10^{-3} \mathrm{~mm}^{2} / \mathrm{s}$. The second chondrosarcoma and the glomus tumor had intermediate ADC values between $\left(1\right.$ and $\left.1.7 \times 10^{-3} \mathrm{~mm}^{2} / \mathrm{s}\right)$. The endolymphatic sac tumor was hypointense on DWI and had ADC value 2.1 $\times 10^{-3} \mathrm{~mm}^{2} / \mathrm{s}$ (Table 4 ).

Out of the 27 patients, six patients had MR perfusion imaging done: Three of which were hypoperfused (two vestibular schwannomas and chondrosarcoma). The other three were hyperperfused (three meningiomas). A hypoperfused curve showed slow upstroke and progressive slope rising above plateau suggestive hypocellular and hypovascular matrix, which retains the contrast. This is in contrast to the hyperperfused curve which shows rapid upstroke followed by $\mathrm{T} 2 *$ recirculation due to susceptibility created by the passage of gadolinium. This is followed by a slow return of the re-circulation curve to the baseline.

Regarding spectroscopic spectral analysis, all the twelve schwannomas $(n=12)$ and a single meningioma $(n=1)$ showed myoinositol peak, while six meningiomas (out of total 7) showed alanine peak. A statistical test showed the statistical significance of metabolite markers of underlying lesions. A myoinositol as a diagnostic marker of schwannoma and alanine as a marker diagnostic of meningioma. Chondrosarcoma and a glomus tumor showed non-specific lactate peaks, while endolymphatic tumor-ELT showed a non-readable spectrum, presumably due to contamination by bone marrow fat. Metabolites of intra-axial lesions (e.g., choline) are not stressed in our study (Table 5).

Final diagnosis was made as follows: eight of ten vestibular schwannomas undergone surgical resection, while two cases of bilateral vestibular schwannomas(NF2) were diagnosed by approved clinico-radiological criteria and genetic testing. Six of seven meningiomas were resected, with the last case reserved for follow-up. Facial schwannoma and trigeminal schwannomas reserved for follow-up. The two epidermoid cysts are resected. The arachnoid cyst is left for follow-up. The glomus jugulare tumor was resected. The two chondrosarcomas and the endolymphatic sac tumor were diagnosed by endoscopic biopsy. The decision for the metastatic case was followed up as part of the leukemia

Table 3 Evaluation of different conventional signs of CPA masses

\begin{tabular}{|c|c|c|c|c|c|c|c|c|}
\hline & \multicolumn{6}{|c|}{ Diagnosis } & \multirow[t]{3}{*}{$x^{2}$} & \multirow[t]{3}{*}{${ }^{M C_{p}}$} \\
\hline & \multicolumn{2}{|c|}{ Schwannoma $(n=12)$} & \multicolumn{2}{|c|}{ Meningioma $(n=7)$} & \multicolumn{2}{|c|}{ Other $(n=8)$} & & \\
\hline & No. & $\%$ & No. & $\%$ & No. & $\%$ & & \\
\hline Extension into IAC & 10 & 83.3 & 5 & 71.4 & 2 & 25.0 & $6.785^{*}$ & $0.032^{*}$ \\
\hline Flaring of IAC & 10 & 83.3 & 0 & 0.0 & 1 & 12.5 & 16.181 & $<0.001$ \\
\hline Dural tail & 3 & 25.0 & 7 & 100.0 & 1 & 12.5 & 13.773 & $<0.001$ \\
\hline Extra-cranial extension & 0 & 0.0 & 2 & 28.6 & 2 & 25.0 & 4.042 & 0.125 \\
\hline
\end{tabular}

$\mathrm{X}^{2}$ chi-square test, MC Monte Carlo

$\mathrm{p}$ : $p$ value for association between different categories

*Statistically significant at $p \leq 0.05$ 


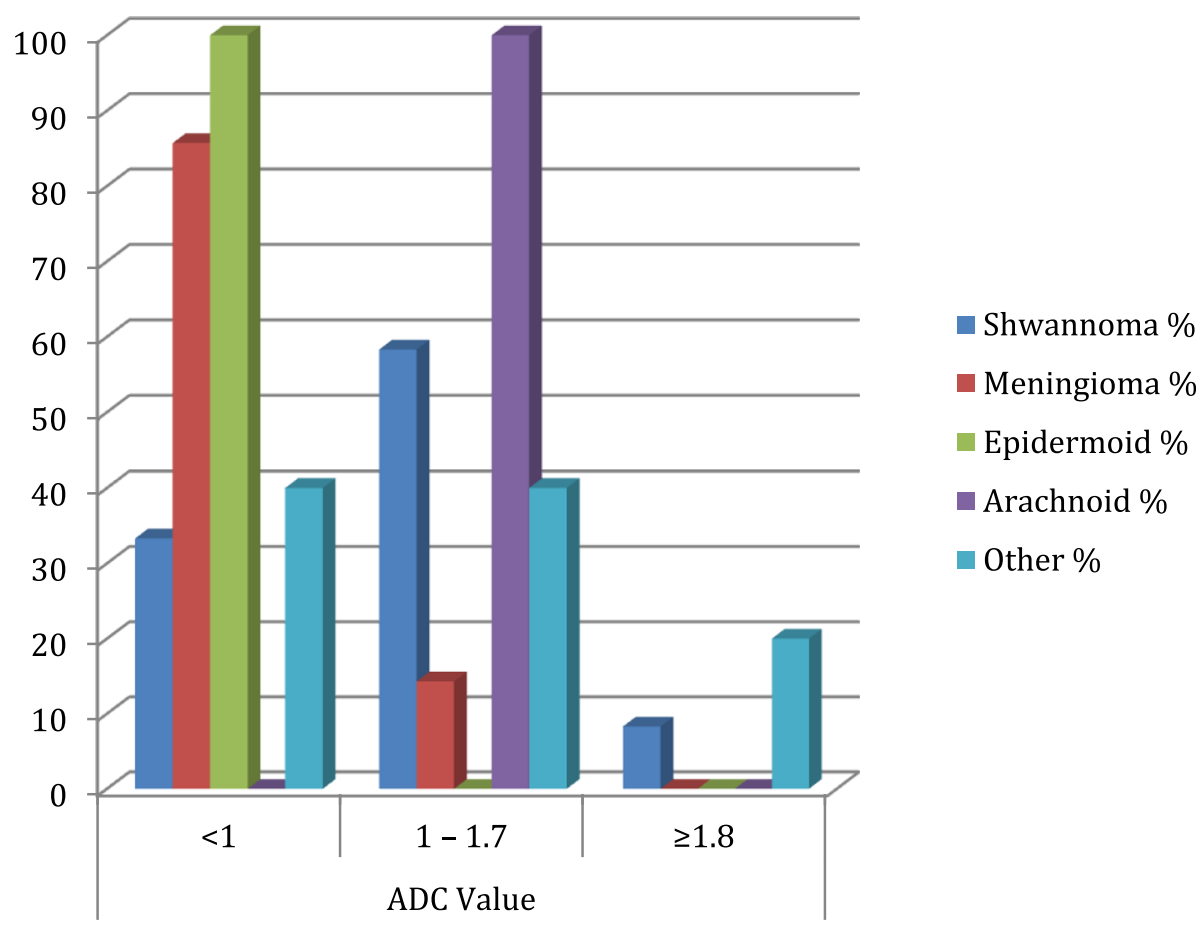

Fig. 1 Chart showing the distribution of ADC values among different CPA pathologies

management plan. Follow-up of CPA masses is usually made at 6-12 months according to clinical and radiological criteria for patient status and for tumor type and size.

As the study is emphasizing schwannomas and meningiomas, the findings of both pathologies are detailed: The study included twelve schwannomas $(n=12)$ : Ten are vestibular $(n=10)$, one facial $(n=1)$, one trigeminal $(n=1)$. The ten vestibular schwannomas detailed as (a) eight (80\%) hyperintense, 1 (10\%) bright, and one (10\%) iso-intense on T2WI, (b) eight (80\%) were hyperenhancing after contrast administration: Five (62.5\%)

Table 4 Evaluation of different conventional signs of CPA masses

\begin{tabular}{|c|c|c|c|c|c|c|}
\hline & \multicolumn{4}{|c|}{ Diagnosis } & \multirow[t]{3}{*}{$x^{2}$} & \multirow[t]{3}{*}{${ }^{M C} p$} \\
\hline & \multicolumn{2}{|c|}{$\begin{array}{l}\text { Schwannoma } \\
(n=12)\end{array}$} & \multicolumn{2}{|c|}{$\begin{array}{l}\text { Meningioma } \\
(n=7)\end{array}$} & & \\
\hline & No. & $\%$ & No. & $\%$ & & \\
\hline \multicolumn{7}{|l|}{ Diffusion } \\
\hline Hyper & 4 & 33.3 & 7 & 100.0 & $7.359^{*}$ & $0.019^{*}$ \\
\hline Iso & 6 & 50 & 0 & 0.0 & & \\
\hline Нуро & 2 & 16.7 & 0 & 0.0 & & \\
\hline \multicolumn{7}{|c|}{ ADC value } \\
\hline$<1$ & 1 & 8.3 & 4 & 57.2 & $5.135^{*}$ & $0.042^{*}$ \\
\hline $1-1.7$ & 10 & 83.4 & 3 & 42.8 & & \\
\hline$\geq 1.8$ & 1 & 8.3 & 0 & 0.0 & & \\
\hline
\end{tabular}

$x^{2}:$ chi-square test, $M C$ Monte Carlo

$p: p$ value for association between different categories showed homogenous enhancement and three (37.5\%) showed heterogeneous enhancement. One (10\%) vestibular schwannoma was hypo-enhancing and another (10\%) showed rim enhancement, (c) four (40\%) showed cystic changes, (d) three (30\%) were hyperintense in diffusion image, six $(60 \%)$ iso-intense, one $(10 \%)$ hypointense, (e) nine (90\%) had ADC values between 1 and 1.7 $\times 10^{-3} \mathrm{~mm}^{2} / \mathrm{s}$ and $1(10 \%)$ had ADC value $<1 \times 10^{-3}$ $\mathrm{mm}^{2} / \mathrm{s}$, (f) five cases of vestibular schwannomas had SWI signal voids, $(\mathrm{g})$ all cases $(n=10)$ are encasing the 8th nerve on CISS, (h) all $(n=10)$ showed myoinositol peak and one showed additional lactate/lipid peak, (i) perfusion performed on 3 cases revealed hypoperfused curve, (j) nine (90\%) acoustic schwannomas showed extension into the IAC with flaring, (k) three (30\%) showed dural tail after contrast enhancement. Refer to Figs. 2 and 3 showing cases of vestibular schwannomas.

Table 5 Comparison of myo-inositol and alanine peaks on MRS between meningiomas and schwannomas

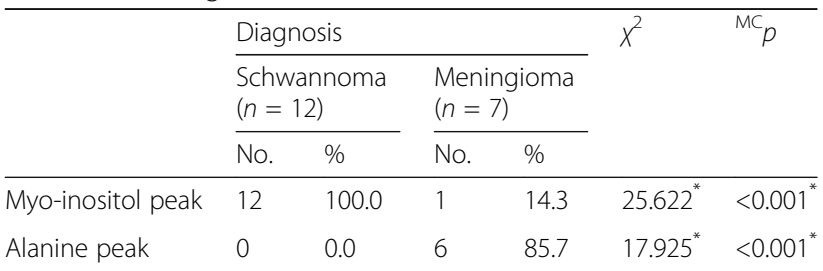

$x^{2}$ : chi-square test, $M C$ Monte Carlo $p: p$ value for association between different categories *Statistically significant at $p \leq 0.05$ 


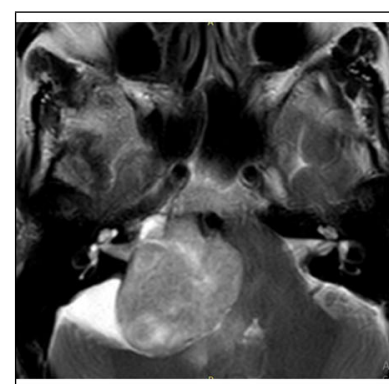

(a)

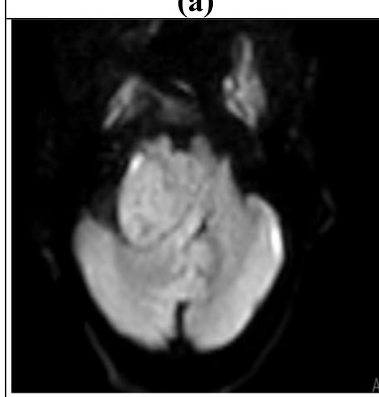

(d)

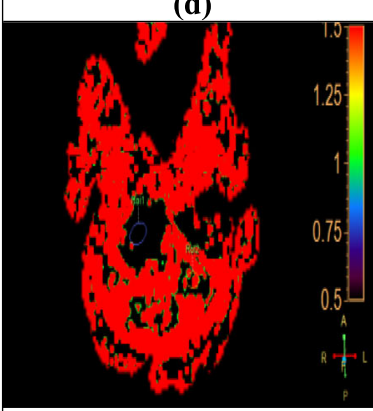

(g)

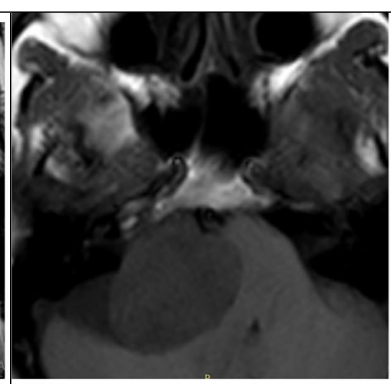

(b)

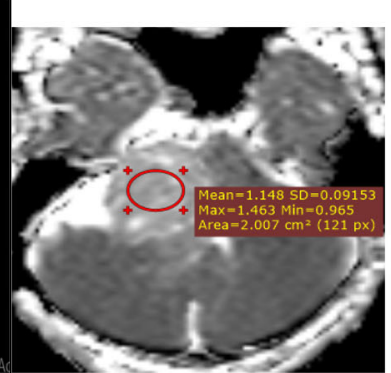

(e)

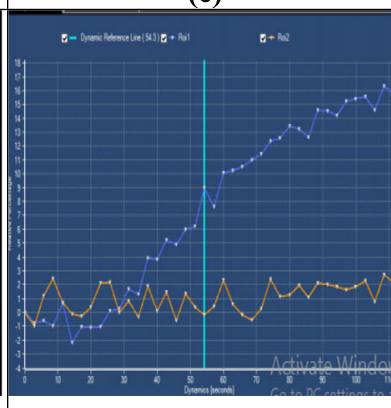

(h)

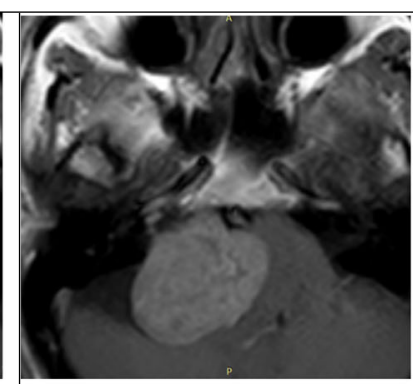

(c)

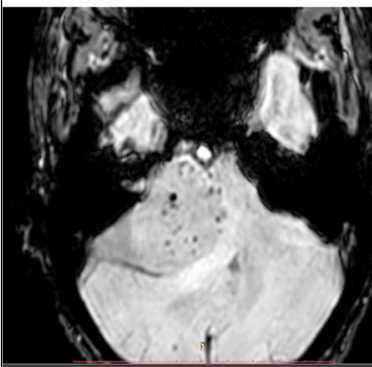

(f)

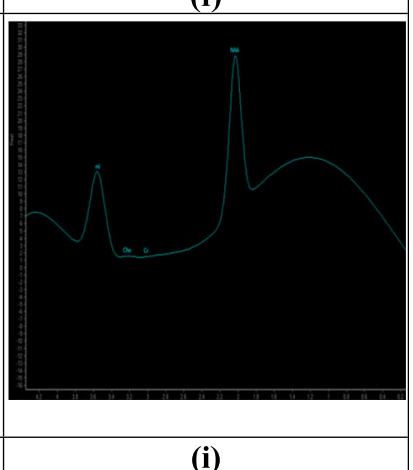

Fig. 2 A 60-years-old male presented with right sensorineural hearing loss. A right CPA space-occupying lesion is seen. This is hyperintense on T2WI (a), hypointense on T1WI (b), showing homogenous, solid and moderate post-contrast enhancement on T1WI+C (c), hyperintense on diffusion image $(\mathbf{d})$ showing intermediate ADC value $1.14 \times 10^{-3} \mathrm{~mm}^{2} / \mathrm{s}(\mathbf{e})$, signal voids on SWI (f), showing hypoperfusion in perfusion map (g) and hypoperfused curve on PWI (h), with myo-inositol peak on MRS (i). The findings were matching with the final diagnosis of the right CPA schwannoma

Meningiomas $(n=7)$ showed the following: (a) four (57.2\%) were T2 hyperintense and three (42.8\%) was isointense on T2WI, (b) all the seven (100\%) were homogenously hyper-enhancing with no cystic changes, (c) All the seven $(100 \%)$ were hyperintense on DWI, (d) four (57.2\%) had ADC values less than $1 \times 10^{-3} \mathrm{~mm}^{2} / \mathrm{s}$ and three $(42.8 \%)$ had ADC value between 1 and $1.7 \times 10^{-3}$ $\mathrm{mm}^{2} / \mathrm{s}$, (e) five cases had SWI done; none of which showed signal voids, (f) four (57.1\%) cases were encasing 8th nerve, one (14.3\%) showed contact, while one (14.3\%) was displacing it. The nerve was not involved with one case $(14.3 \%)$, (g) six cases $(85.7 \%)$ showed alanine peak, and a single case showed myoinositol peak, (h) three showed hyperperfused curves, (h) five (71.4\%) cases showed extension into the IAC; none showed flaring of the IAC, (i) all the seven (100\%) showed dural tail and two (28.6\%) showed extra-cranial extension. Refer to Fig. 4 showing imaging features of meningioma.

The single case of trigeminal schwannoma showed typical features similar to the vestibular variant (Fig. 5). Also, morphological and functional features of one of two chondrosarcomas and the single paraganglioma are shown in Figs. 6 and 7, respectively.

\section{Discussion}

CPA masses are usually uncommon lesions. This accounts for the small sample size of our study. Though our study showed no significant sex predominance, it showed some preponderance in the fourth and fifth decades. This agrees with studies made by Sonowal et al. [27] and Haque et al. [39], who reported that the peak incidence of CPA masses to be in the fifth decade. Still, 


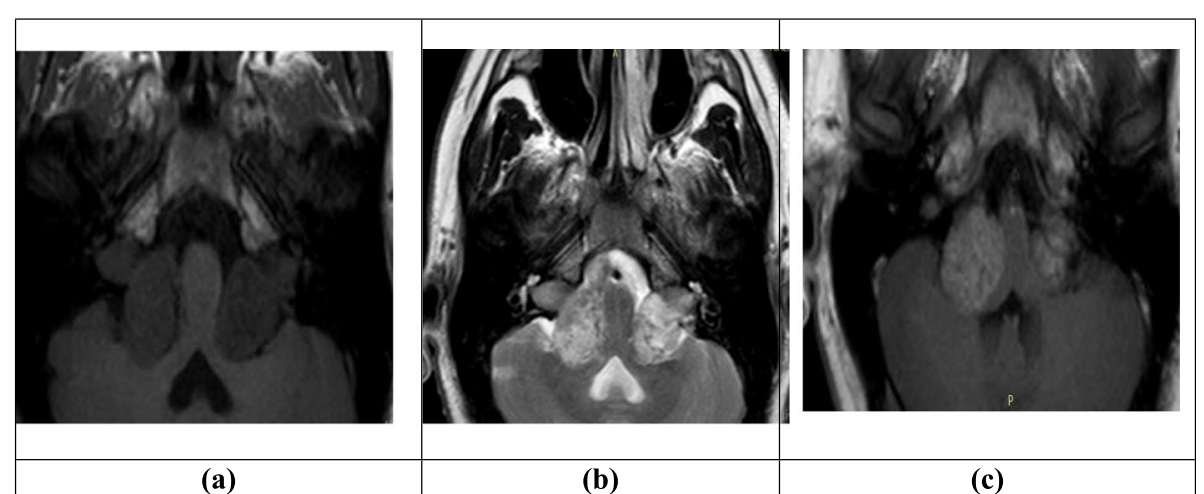

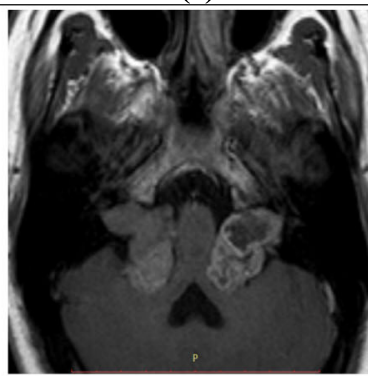

(d)

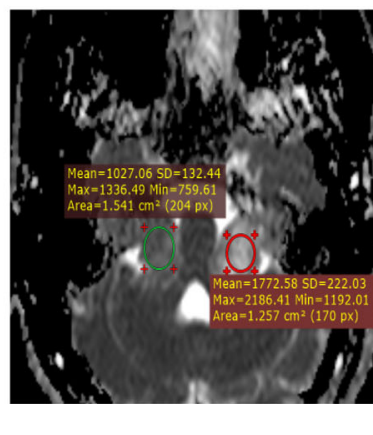

(g)

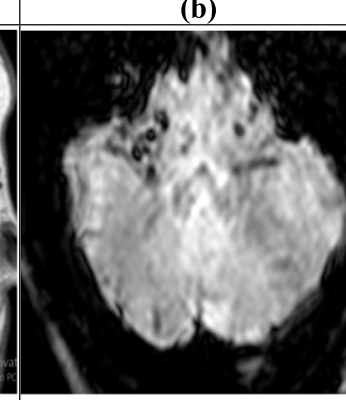

(e) (c)

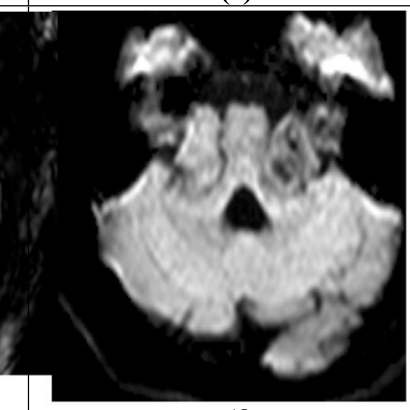

(f)

Fig. 3 A 21-years-old male patient with a known diagnosis of NF2 came for follow-up. Bilateral CPA space-occupying lesions are seen. They are hypointense on T1WI (a), hyperintense, extending into and widening the IACs on T2WI (b), showing heterogenous post-contrast enhancement on $\mathrm{T} 1 \mathrm{WI}+\mathrm{C}(\mathbf{c}, \mathbf{d})$, showing signal voids of micro-bleeds on SWI $(\mathbf{e}, \mathbf{f})$. The right mass shows hyperintense signal in diffusion with $\mathrm{ADC}$ value $=1.2$ $\times 10^{-3} \mathrm{~mm}^{2}$. The left is hypointense on DWI with ADC value of $1.5 \times 10^{-3} \mathrm{~mm}^{2}(\mathbf{g})$. They showed myo-inositol peak on MRS. The findings were matching with the final diagnosis of NF2 with bilateral CPA schwannomas

Mersha HB [5], Maaly et al. [8], and Singh et al. [35] reported younger peak incidence in the third and fourth decade [5, 8, 35]. Our study included 14 males and 13 females, with a nearly $1: 1$ ratio. In agreement with a study by Mersha et al. [5], our study showed no gender predilection. However, it did not agree with Singh et al. [35], who reported female predominance, while Hari et al. [36] reported slight male preponderance. The absence of gender predilection in our study is most probably due to the small sample size.

The most common presenting symptom in our study was sensorineural hearing loss (37.1\%). This agreed with most of the reported studies including Shakweer et al. [6], Maaly et al. [8], who reported a sensorineural hearing loss as the most common presenting symptom in CPA masses.

As expected, acoustic schwannoma represented the most common CPA lesion (37\%), followed by meningioma (25.9\%). This correlated well with most of the prior studies conducted by Shakweer et al. [6], Maaly et al. [8], and Springborg et al. [40]. The third commonest lesions were both epidermoid cyst and chondrosarcoma; the last two mentioned occurred in equal proportions (7.4\%). The epidermoid cyst constituted the third commonest in most of the studies, while chondrosarcomas were unexpectedly equal to epidermoid in incidence. Also, our study also included one arachnoid cyst (3.9\%), one glomus tumor $(3.7 \%)$, one metastasis $(3.7 \%)$, one 


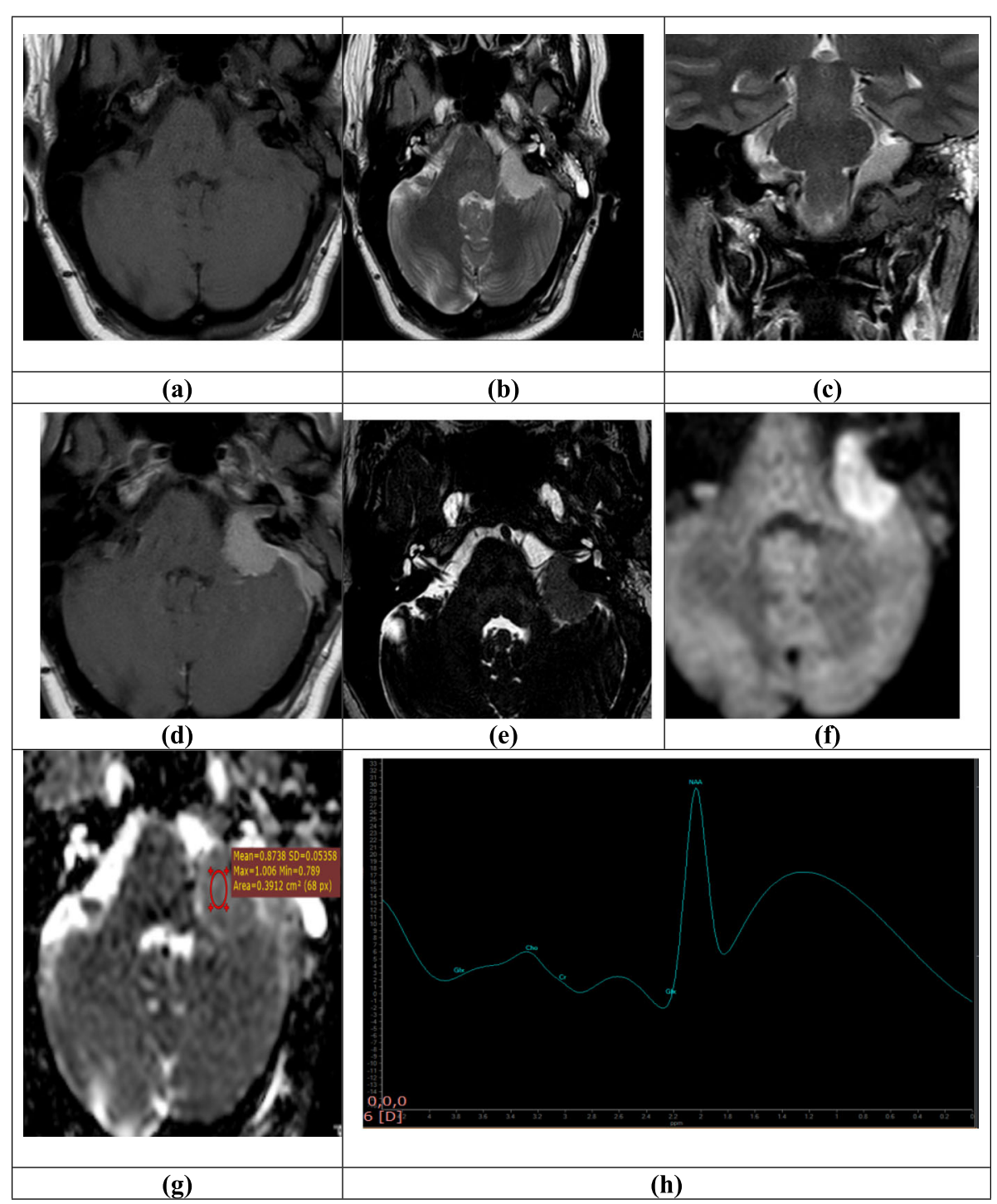

Fig. 4 A 31-years-old female with left CPA space mass lesion. The mass is seen iso-intense on T1WI (a), T2 hyperintense and extending into the IAC without widening $(\mathbf{b}, \mathbf{c})$, showing homogenous post-contrast enhancement, with a dural tail on $T 1 \mathrm{WI}+\mathrm{C}(\mathbf{d})$, displacing the 8 th cranial nerve on CISS (e), hyperintense on DWI (f), low ADC value $0.8 \times 10^{-3} \mathrm{~mm}^{2}(\mathbf{g})$, expressing alanine peak on MRS (h). The T2 hyperintense signal was not usual for meningioma still broad-based appearance and dural base suggested meningioma, with additional support by spectroscopy and diffusion data. Surgical resection revealed meningioma

endolymphatic sac tumor (3.7\%), one trigeminal schwannoma (3.7\%), and one facial schwannoma (3.7\%).

The most prevalent lesions; schwannomas, counted twelve in number: ten arose from the vestibular nerve, one from the facial nerve, and last one from the trigeminal nerve. The imaging features of vestibular schwannomas are discussed in the following section, while VII and $\mathrm{V}$ schwannomas are discussed later with uncommon lesions. Regarding T1 signal of schwannoma: all are hypointense on T1WI. For T2 signal, eight (80\%) were hyperintense, one (10\%) was bright, and one (10\%) was iso-intense on T2WI. This is expected for hypocellular nature and high fluid content that prolongs the relaxation of the lesion in $\mathrm{T} 2$ and shortens in $\mathrm{T} 2$. Our findings correlated well with Shakweer et al. [6] reported $78.5 \%$ of acoustic schwannomas to be hypointense on T1WI. Maaly et al. [8] reported that the majority of acoustic schwannomas were been iso-intense on T1WI (91.7\%) and on T2WI (58.3\%). On the other hand, Haque et al. [39] reported $84 \%$ of acoustic schwannoma to be hyperintense on T2WI.

Following GAD, vestibular schwannomas showed variable patterns of enhancement. Eight vestibular schwannomas (80\%) were hyper-enhancing after contrast administration: five (62.5\%) homogenous and three (37.5\%) showed heterogeneous enhancement. One 


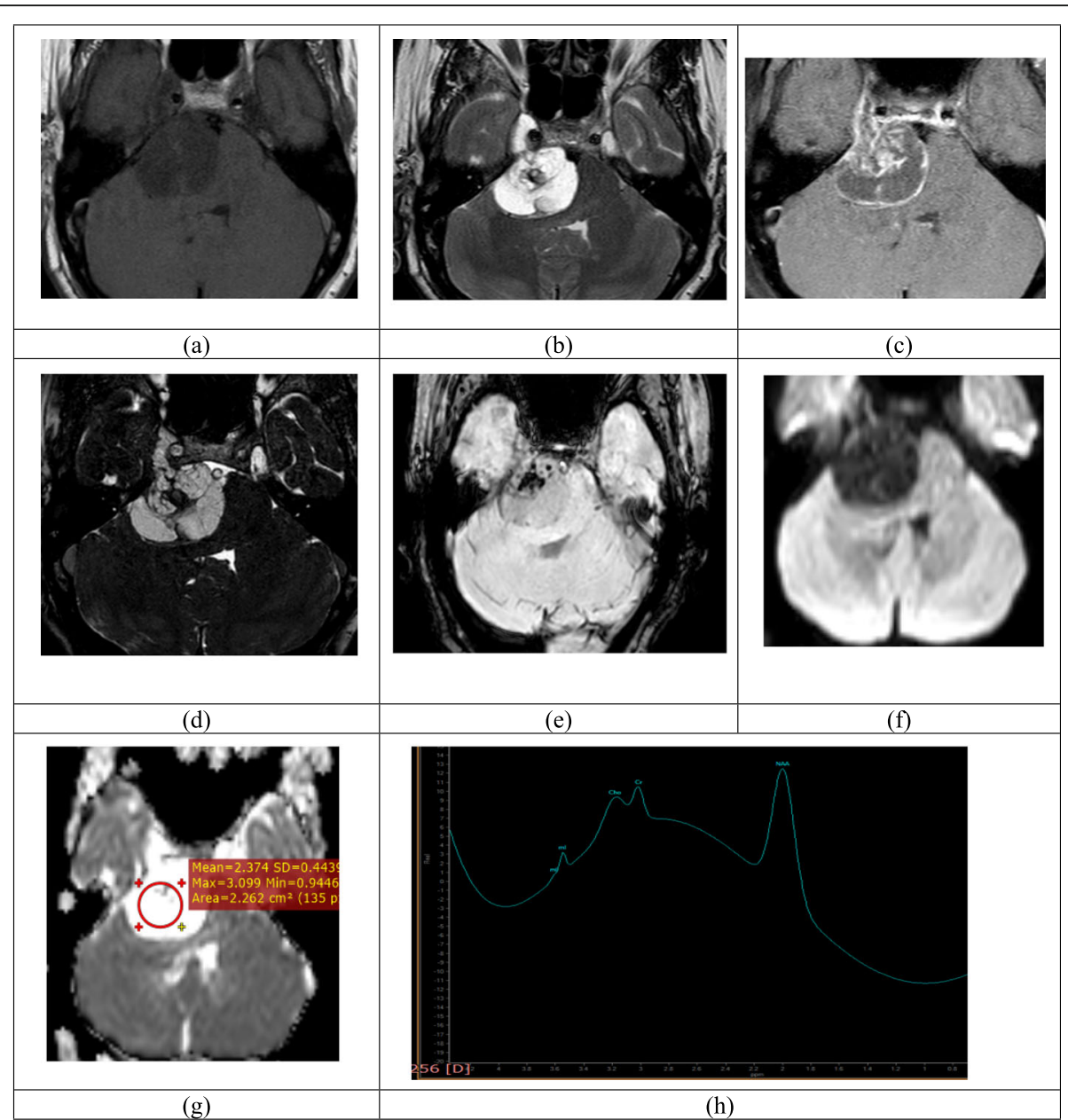

Fig. 5 A 22-years-old male patient with a right CPA mass. This is seen hypointense on T1WI (a), hyperintense with hypointense foci (likely due to hemorrhage) on $\mathrm{T} 2 \mathrm{WI}(\mathbf{b})$, showing heterogenous post-contrast enhancement, with $\mathrm{T} 1 \mathrm{WI}+\mathrm{C}(\mathbf{c})$, extending along and encasing the 5 th cranial nerve reaching Meckel's cave on CISS (d), showing signal voids on SWI (e), hypointense on DWI (f) with high ADC value $2.3 \times 10^{-3} \mathrm{~mm}^{2} / \mathrm{s}(\mathbf{g})$ showing myo-inositol peak on MRS (h). These findings were matching with the final diagnosis of the right CPA trigeminal schwannoma

vestibular schwannoma showed (10\%) hypo-enhancement and another one (10\%) showed "rim enhancement". The variable enhancement patterns of acoustic schwannomas correlated with literature reported findings reported by Shakweer et al. [6], Kapoor et al. [38], Haque et al. [39], and Maaly et al. [8], the latest reported acoustic schwannoma to show homogenous hyperenhancement in approximately $57 \%$ of the cases and heterogeneous enhancement in $43 \%$ of the cases. Though intracanalicular extension is not specific, statistical significance revealed the sign of flaring to be significant as a marker of VS. Three (30\%) acoustic schwannomas showed dural tail after contrast enhancement. On the contrary, all meningiomas $(n=7)$ showed a dural tail. Still, a statistical significance test revealed dural tail is significantly expressed in meningiomas, versus IAC extension as being a sign of acoustic schwannoma.
In our study, $60 \%$ of acoustic schwannomas $(n=10)$ were iso-intense on diffusion image and $90 \%$ of them ( $n$ =9) had ADC values ranging between 1 and $1.7 \times 10^{-3}$ $\mathrm{mm}^{2} / \mathrm{s}$, with a mean value of $1.3 \times 10^{-3} \mathrm{~mm}^{2} / \mathrm{s}$. A study by Farhan et al. [41], reported $61 \%$ of their cases to be iso-intense on DWI, still having a higher mean ADC value of $1.61 \times 10^{-3} \mathrm{~mm}^{2} / \mathrm{s}$, meaning that schwannomas are generally not restricted and instead are mainly diffusive on DWI. Also, a study by Pavlisa et al. [42] reported a mean ADC value of $1.67 \times 10^{-3} \mathrm{~mm}^{2} / \mathrm{s}$. The higher $\mathrm{ADC}$ of schwannomas is probably related to less cellular areas of the tumor. In larger schwannomas, there is a predominance of the loose textured and cystic areas (Antoni type B), resulting in higher water diffusion [41, 42]. However, in smaller schwannomas, there is a predominance of Antoni type A cells mounting to highly cellular tumors and thus lower ADC values and this may be the cause of low ADC values in some schwannomas. 


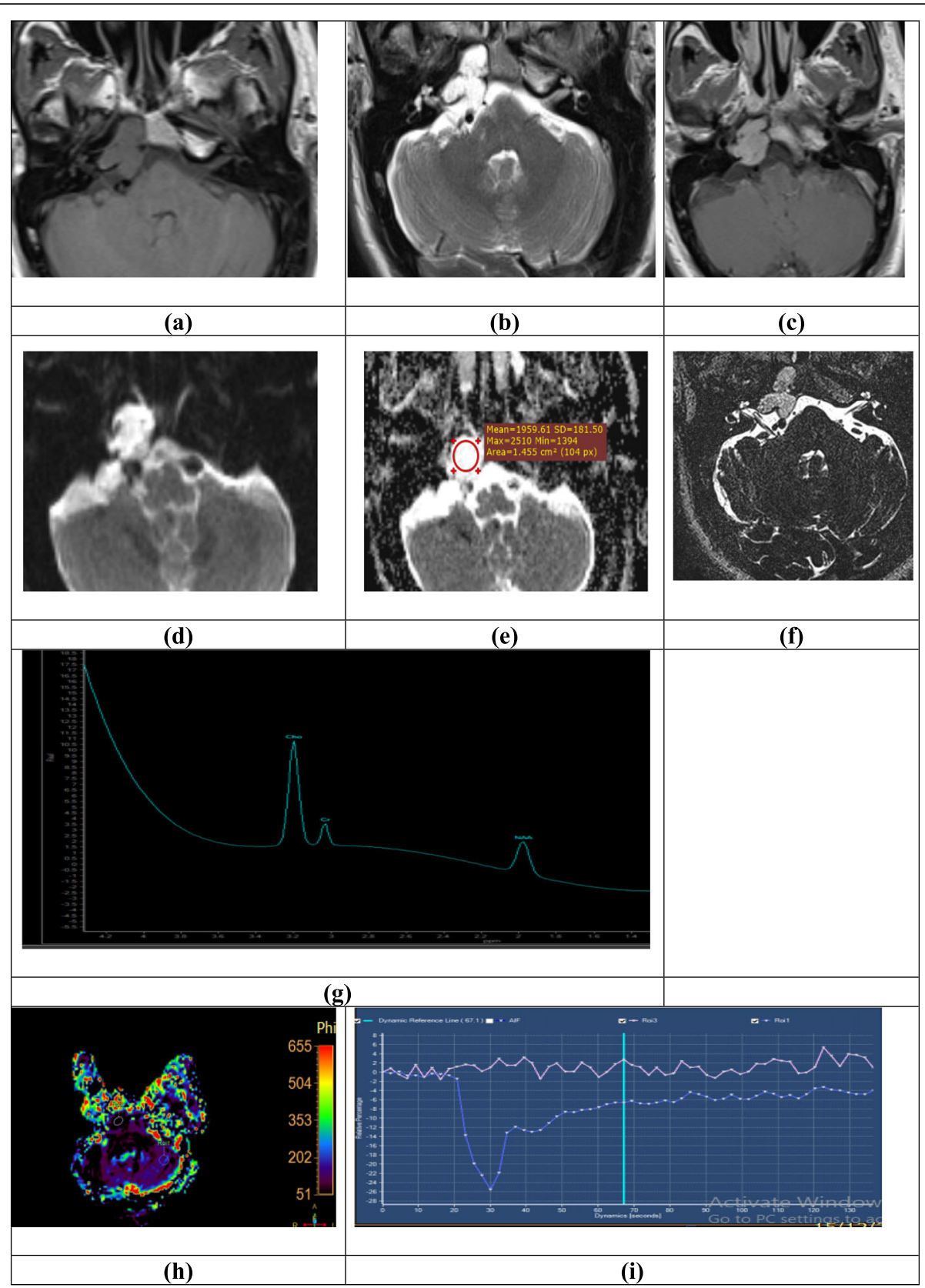

Fig. 6 A 42-years-old male patient presented with a headache. Images revealed a right CPA mass involving the clivus bone on one side (offaxial), iso-intense on T1WI (a), hyperintense on T2WI (b), showing homogenous post-contrast enhancement, on T1WI+C (c), seen hyperintense with hypointense foci on DWI with ADC value $2 \times 10^{-3} \mathrm{~mm}^{2} / \mathrm{s}(\mathbf{d}, \mathbf{e})$, not involving the 8th nerve on CISS (f), showing high choline peak on MRS (g) hypoperfused on MRP map and curve $(\mathbf{h}, \mathbf{i})$. These findings were matching with the final diagnosis of right chondrosarcoma

Thus, schwannomas have a wide range of restriction and ADC values; the majority usually show mild restriction and ADC values more than $1 \times 10^{-3} \mathrm{~mm}^{2} / \mathrm{s}$ [43]. Our measured ADCs values are yet smaller than comparable literature results, likely due to more cellular variants. This variable cellular pathology can also explain for the variegated T2-signals of schwannomas. This can be displayed as iso-intense hyperintense and even bright. Also, variable enhancement pattern is likely also explained by the variable cellular pattern; the higher cellularity correlated is linked to intense contrast enhancement as a result of more tumoral cellular uptake. On the other hand, the hypocellular nature of lesions could lead to lower uptake of interstitial contrast and thus hypoenhancement, or may paradoxically allow for retention and accumulation of contrast in the loose hypocellular stroma and thus hyper-enhancement of the mass. However, in perfusion (PWI), the intravascular bolus depends 


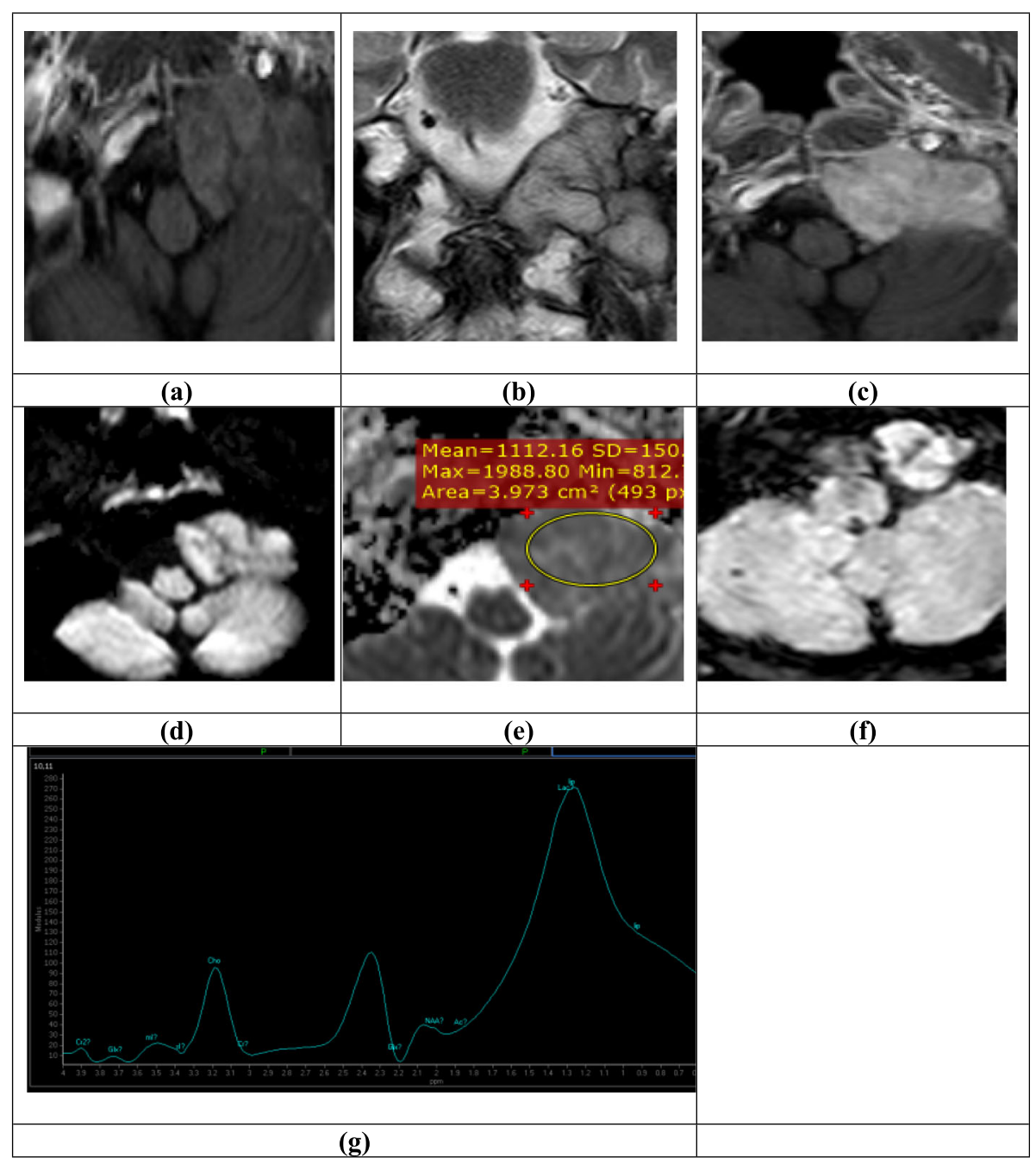

Fig. 7 A 38-years-old female with left pulsatile tinnitus. A left CPA mass is seen likely an extension from jugular foramen (widened and destroyed on $(\mathrm{T})$. This is iso-intense on T1WI (a), hyperintense on T2WI and showing salt and pepper appearance (b), showing avid post-contrast enhancement on T1WI+C (c), hyperintensity on DWI with ADC value $1.1 \times 10^{-3} \mathrm{~mm}^{2} / \mathrm{s}(\mathbf{d}, \mathbf{e})$, foci of blooming on SWI (f) and high choline and lactate peaks on MRS $(\mathbf{g})$. Conventional imaging findings are typical of the final post-excisional biopsy of the left glomus jugulare tumor. Additional imaging data of spectroscopy septra was non-specific

on intravascular and not interstitial uptake of the contrast and the generated curves depend on vascular network density. So, schwannomas are expected to show a hypoperfused curve which a slow upstroke and progressive slope rising above plateau [43-45]. This hypoperfusion pattern was seen in two of the schwannomas in our study.

The role of CISS was only to evaluate the neural contact of CPA mass with the vestibulocochlear nerve. In our study, all the acoustic schwannomas (100\%) were encasing the vestibulocochlear nerve; the latter not identified separately with evidence of neuronal degeneration in one case. Nine (90\%) acoustic schwannomas showed extension into the IAC with smooth flaring. The CISS and 3D diffusion with variable $B$-values show the smallest $6 \mathrm{~mm}$ lesion, which was diagnosed as a meningeal leukemic deposit $(6 \mathrm{~mm})$.
In SWI images (done in 18 cases), three out of five schwannomas $(60 \%)$ showed blooming signal voids, which are not calcifications. Saravanan et al. [23] reported SWI-related blooming in all their schwannoma cases and none in meningiomas [23]. A similar study by Mishra et al. [43] reported blooming voids in all schwannomas while a single meningioma showed blooming that proved to be calcifications on CT [43]. The etiopathogenesis of these non-calcified blooming signal voids is yet not clarified, still, the different hypothesis suggests them to be mixed micro-bleed and fibrous stroma. Moreover, these were suggested as the precursor of cystic changes in schwannomas and could be quite differentiating point of the schwannomas. None of the meningiomas in our study revealed signal voids [43]. 
The second commonest lesion, "meningiomas", counted seven cases (25.9\%). In T2WI, six lesions $(85.7 \%)$ were unexpectedly hyperintense and one case (14.3\%) was iso-intense on T2WI. This finding disagreed with most literature, including made by Shakweer et al. [6] and Maaly et al. [8], who stated that meningiomas were $\mathrm{T} 2$-iso-intense in $66.6 \%$ and $71.4 \%$ of their cases, respectively $[6,8]$. Still, our finding agreed with a study by matching Mersha et al. [5], who reported $80 \%$ of their cases to be $\mathrm{T} 2$ hyperintense. The variability in $\mathrm{T} 2$ signal intensities of meningioma is due to their different histologic subtypes (fibroblastic, transitional, syncytial, angioblastic, or mixed) where each subtype results in different T2 signal intensity. Syncytial and angio-blastic subtypes have hyperintense T2 signal where the remaining types have iso-intense to hypointense T2 signal [25].

Also, all the seven meningiomas (100\%) were homogenously hyper-enhancing with no cystic changes. All the seven meningiomas (100\%) were hyperintense on DWI. Four (57.2\%) had low ADC values less than $1 \times 10^{-3}$ $\mathrm{mm}^{2} / \mathrm{s}$ and three $(42.8 \%)$ had intermediate ADC value between 1 and $1.6 \times 10^{-3} \mathrm{~mm}^{2} / \mathrm{s}$. Farhan et al. [41] reported $77.8 \%$ of their meningioma case to be iso-intense on DWI, with a low ADC value of $0.97 \times 10^{-3} \mathrm{~mm}^{2} / \mathrm{s}$. Similar low to intermediate ADC values were reported by Pavlisa et al. [42], ranging between 0.87 and $1.1 \times 10^{-3} \mathrm{~mm}^{2} / \mathrm{s}$.

Comparing ADCs of meningiomas and vestibular schwannomas: Schwannomas had prevalent values in the range of $1-1.7 \times 10^{-3} \mathrm{~mm}^{2} / \mathrm{s}$ (nine out of ten) with an additional single case of $<1 \times 10^{-3} \mathrm{~mm}^{2} / \mathrm{s}$. Comparatively, meningiomas displayed more restricted low ADC values, nearly $60 \%$ showing ADC $<1 \times 10^{-3} \mathrm{~mm}^{2} / \mathrm{s}$. These results are in good agreement with those published by Farhan et al. [41] and Pavlisa et al. [42]. Thus, it is obvious that meningiomas almost always restrict with low to intermediate ADC values generally lower than that of schwannomas. Our statistical analytical tests revealed a statistical significance of different ADC values that separate the two pathologies: meningiomas and schwannomas, being lower for the former mentioned. Still, there may be an overlap of both lesions in intermediate ADC values reflected by high cellular schwannomas.

Comparing MRS applied in our study, all acoustic schwannomas (100\%) showed myo-inositol peak and one case showed lactate/lipid peak. Shakweer et al. [6] reported that schwannomas showed myo-inositol peak and high choline peak. They also stated the cause of the presence of myoinositol peak in schwannomas is unknown. However, it is likely because myo-inositol exists in schwann cells and is associated with microglial activation and astrogliosis, a feature that is present in schwannoma. The lipid peak that was seen in a schwannoma case may be attributed to intralesional cystic changes or necrosis. However, it is not specific for diagnosing schwannoma. Comparatively, six cases of meningiomas (85.7\%) showed alanine peak and one (14.3\%) case showed myo-inositol peak. Shakweer et al. [6] also reported that meningiomas showed alanine and glutamate peaks as well as high choline peak and low NAA peak. Gujar et al. [45] reported that meningiomas showed alanine peak, high choline peak, low NAA peak, and sometimes glutamate peak at $2.35 \mathrm{ppm}$.

The three epidermoid and arachnoid cysts in our study showed typical literature-described features of nonenhancement, with nulling on FLAIR by arachnoid and marked diffusion hyperintensity of epidermoid showing low ADC of $0.6 \times 10^{-3} \mathrm{~mm}^{2} / \mathrm{s}$. Still, spectroscopy analysis of our epidermoid was distorted and non-readable, compared to research by Poptani et al. [44], reported some lactate peak in these cystic lesions.

The two cases of chondrosarcomas had osseous epicenters at the petrous apex with intradural extra-axial component pedunculated and secondarily extending into CPA. They showed a bright chondroid matrix on T2WI with avid enhancement. MR perfusion performed on one case was hypoperfused as expected for its matrix. Such conventional and functional data just correlated with findings reported by Kothary et al. [46]. Also, both lesions showed high ADC values of $1.5 \times 10^{-3} \mathrm{~mm}^{2} / \mathrm{s}$, which is helpful to differentiate such lesions from offline chondromas; the latter showing lower values of 1.2 $\times 10^{-3} \mathrm{~mm}^{2} / \mathrm{s}$, as reported by Muller et al. [47] while chondrosarcoma have a mean higher ADC values up to $2.1 \times 10^{-3} \mathrm{~mm}^{2} / \mathrm{s}$. Though Kumaran et al. [48] reported NAA peak in chondrosarcoma, our case revealed nonspecific lactate peaks at all. This may be attributable to many to bone/air interfaces degrading spectra.

The glomus jugular lesion pedunculated as CPA mass showed typical salt and pepper appearance with avid enhancement and unexpectedly intermediate ADC of $1.11 \times$ $10^{-3} \mathrm{~mm}^{2} / \mathrm{s}$, questionably due to hemorrhages and fibrosis intervening between the vascular spaces inside the lesion. Aschenbach et al. [49] reported glomus tumors to have a mean ADC value of $1.3 \pm 0.2 \times 10^{-3} \mathrm{~mm}^{2} / \mathrm{s}$. Spectrum from glomus revealed a high choline/creatine ratio and a lactate peak. Maheshwari et al. [50] who reported a glomus tumor to be a benign tumor with a high choline/creatine ratio. The trigeminal schwannoma showed T2 bright signal and hyper-enhancement with a high ADC value 2.3 $\times 10^{-3} \mathrm{~mm}^{2} / \mathrm{s}$. The facial schwannoma shows T2 hyperintense signal with an intermediate ADC value of ADC value $1.2 \times 10^{-3} \mathrm{~mm}^{2} / \mathrm{s}$, seen continuous with dilated fallopian/VII canal. These were just similar to published literature criteria [51, 52]. A limitation for our study is the small sample size with only a total of 27 patients, 12 schwannomas, and only 7 meningiomas. It is recommended for additional work of a larger patient sample size and with the incorporation of other dedicated techniques (e.g., $\mathrm{T}^{*}$ dynamic perfusion). 


\section{Conclusions}

Though MRI features of CPA masses are distinctive in most clinical settings, MRI spectroscopy, diffusion, and susceptibility can provide highly informative additional data in problematic cases. An intermediate to high ADC value plus myo-inositol peak and signal voids of microbleeds are highly suggestive of schwannomas. This is in contrary to meningiomas displaying low to intermediate $\mathrm{ADC}$ and an alanine peak with no micro-bleeds. The less common lesions revealed non-specific data.

\section{Abbreviations \\ CPA: Cerebello-pontine angle; ADC: Apparent diffusion coefficient; MRS: Magnetic resonance spectroscopy; NF2: Neurofibromatosis; CISS: Constructive interference in steady state; DWI: Diffusion-weighted imaging; SWI: Susceptibility-weighted imaging; MRP: Magnetic resonance perfusion; IAC: Internal Auditory canal; EST: Endolymphatic sac tumor; FOV: Field of view; CBV: Cerebral blood volume; $r$ rCBV: relative cerebral blood volume; FLAIR: Fluid Attenuated Inversion Recovery; rTBV: Relative tumoral blood volume; MIP: Maximum Intensity Projection; VS: Vestibular schwannomas; CSF: Cerebrospinal fluid; VOI: Volume of interest; NAA: N- Acetyl-cysteine ( $n=$ amino-acid); GAD: Gadolinium (MR contrast); ELT: Endolymphatic tumor}

\section{Acknowledgements}

Not applicable.

\section{Authors' contributions}

MK gave the idea, collected the cases, retained their final diagnosis, and wrote sections of introduction and discussion. KM supervised the final written manuscript. LE made the discussion and analytic analysis WS provided the final post-surgical diagnosis. All authors read and approved the final manuscript.

\section{Funding}

This study had no funding from any resource.

\section{Availability of data and materials}

The datasets used and/or analyzed during the current study are available from the corresponding author on reasonable request.

\section{Ethics approval and consent to participate}

All procedures followed were in accordance with the ethical standards of the responsible committee on human experimentation (Institutional Review Board (IRB)" of Alexandria General Hospital on $14^{\text {th }}$ February 2017) and with the Helsinki Declaration of 1964 and later versions. The committee's reference number is unavailable (not applicable). No consent was obtained from the patients since it was a retrospective study.

\section{Consent for publication}

All patients included in this research gave written informed consent to publish the data contained within this study.

\section{Competing interests}

The authors declare that they have no competing interests.

\section{Author details}

${ }^{1}$ Department of Diagnostic and Interventional Radiology, Alexandria Faculty of Medicine, Alexandria 21131, Egypt. ${ }^{2}$ Department of Neurosurgery, Alexandria Faculty of Medicine, Alexandria, Egypt.

Received: 17 April 2020 Accepted: 16 July 2020

Published online: 24 July 2020

\section{References}

1. Bonneville F, Savatovsky J, Chiras J. Imaging of cerebellopontine angle lesions: an update (2007) Part 1: enhancing extra-axial lesions. Eur Radio 17(10): 2472-82.
2. Scheau C, Lupescu IG, Popa G, Preda EM (2012) Cerebellopontine angle masses: MRI technique, positive and differential diagnosis. Poster presented at Eduactaional exhibits in proceedings of "European Congress of Radiology"-ECR Vienna, Austria.

3. Bruno E, Meo GL, Caruana G, Bencivinni F, Bartolotta TV (2020) Cerebellopontine angle masses: MR imaging features with radiologicpathologic correlation. Poster presented at Eduactaional exhibits in "online" proceedings of European Congress of Radiology-ECR Vienna, Austria.

4. Yadav P, Jantre M, Thakkar D (2015) Magnetic resonance imaging of cerebellopontine angle lesions. Med J DY Patil Univ 8(6):751-759

5. Mersha H, Kebebew T, Debebe T (2018) Cerebellopontine angle masses: Radiologic-pathology correlation at tikur anbessa specialized hospital and myungsung christian medicalcenter. Ethiop Med J 56(1):37-42

6. Shakweer MM, Abdel Azim MH (2015) Differentiation between the common cerebellopontine angle (CPA) lesions by the new MRI techniques. Al-Azhar Assiut Med J 13(1):1-17

7. Schaller B. Cerebellopontine angle surgery (2003) Part 1: General remarks. HNO 51(4):284-95.

8. Maaly MA, Sultan A (2003) Current role of MRI in cerebellopontine angle masses. Menoufia medical journal 29(1):124-151

9. Farid N (2014) Imaging of vestibular schwannoma and other cerebellopontine angle tumors. Oper Tech Otolayngol Head Neck Surg 25(1):87-95

10. Mathur A, Jain N, Kesavadas C, Thomas B, Kapilamoorthy T (2015) Imaging of skull base pathologies: Role of advanced magnetic resonance imaging techniques. Neuroradiol J 28(4):426-437

11. Westbrook C, Talbot J (2018) MRI in Practice. John Wiley \& Sons, USA

12. Lakshmi M, Glastonboury C (2009) Imaging of the cerebellopontine angle. Neuroimaging clinics 19(3):393-406

13. Bonneville F, Savatovsky J, Chiras J (2007) Imaging of cerebellopontine angle lesions: an update. Part 2: intra-axial lesions, skull base lesions that may invade the CPA region, and non-enhancing extra-axial lesions. Eur Radiol 17(11):2908-2920

14. Hingwala D, Chatterjee S, Kesavadas C, Thomas B, Kapilamoorthy TR (2011) Applications of 3D CISS sequence for problem solving in neuroimaging. Indian J Radiol Imag 21(2):90

15. Chavhan GB, Babyn PS, Jankharia BG, Cheng H-LM, Shroff MM (2008) Steady-state MR imaging sequences: physics, classification, and clinical applications. Radiographics 28(4):1147-1160

16. Roser F, Ebner FH, Danz S, Riether F, Ritz R, Dietz K (2008) Threedimensional constructive interference in steady-state magnetic resonance imaging in syringomyelia: advantages over conventional imaging. J Neurosurg 8(5):429-435

17. Goebell E, Ries T, Kucinski T, Grzyska U, Eckert B, Fiehler J (2005) Screening for cerebellopontine angle tumors: is a CISS sufficient? Eur Radiol 15(2):286291

18. Luypaert R, Boujraf S, Sourbron S, Osteaux M (2001) Diffusion and perfusion MRI: basic physics. Eur J Radiol 38(1):19-27

19. Kadri S, Arooj S, Mohammad AG, Ahmed N, Mahmood T (2019) Cerebellopontine angle masses: a visionary approach. poster presented at educational exhibits in proceedings of "European Congress of Radiology ECR" Vienna, Austria

20. Razek AA, Megahed AS, Denewer A, Motamed A, Tawfik A, Nada N (2008) Role of diffusion-weighted magnetic resonance imaging in differentiation between the viable and necrotic parts of head and neck tumors. Acta Radiol 49(3):364-370

21. Liu C, Li W, Tong KA, Yeom KW, Kuzminski S (2015) Susceptibility-weighted imaging and quantitative susceptibility mapping in the brain. J Magn Reson Imaging 42(1):23-41

22. Haacke EM, Xu Y, Cheng YN, Reichenbach JR (2004) Susceptibility weighted imaging (SWI). Magn Reson Med 52(3):612-618

23. Saravanan K, Parthasarathy EA, Farook AS, Sridharan P, Anand R (2018) Role of Susceptibility Weighted Imaging in Cerebellopontine Angle Schwannoma Vs Meningioma. Int J Contemp Med Sur Radiol 3(2):20-23

24. Zimny A, Sasiadek M (2011) Contribution of perfusion-weighted magnetic resonance imaging in the differentiation of meningiomas and other extraaxial tumors: case reports and literature review. J Neuro-Oncol 103(3):777783

25. Aksoy FG, Lev MH (2000) Dynamic contrast-enhanced brain perfusion imaging: technique and clinical applications. Semin Ultrasound CT MR 21(6): 462-477 
26. Grover VP, Tognarelli JM, Crossey MM, Cox IJ, Taylor-Robinson SD, MCPhail MJ (2015) Magnetic resonance imaging: principles and techniques: lessons for clinicians. J Clin Exp Hepatol 5(3):246-255

27. Sonowal TN, Agarwal S, Choudhury H, Brahma N (2016) Cerebellopontine angle lesions-ct and mr imaging evaluation. J Evol Med Dent Sci 5(91): 6750-6756

28. Bulakbasi N, Kocaoglu M, Örs F, Tayfun C, Üçöz T (2003) Combination of single-voxel proton MR spectroscopy and apparent diffusion coefficient calculation in the evaluation of common brain tumors. Am J Neuroradiol 24(2):225-233

29. Dunn IF, Bi WL, Erkmen K, Kadri PA, Hasan D, Tang C (2014) Medial acoustic neuromas: clinical and surgical implications. J Neurosurg 120(5):1095-1104

30. Salzman KL, Davidson HC, Harnsberger HR, Glastonbury CM, Wiggins RH, Ellul S et al (2001) Dumbbell schwannomas of the internal auditory canal. Am J Neuroradiol 22(7):1368-1376

31. Gomez-Brouchet A, Delisle M, Cognard C, Bonafe A, Charlet J, Deguine O et al (2001) Vestibular schwannomas: correlations between magnetic resonance imaging and histopathologic appearance. Otol Neurotol 22(1): 79-86

32. Bonneville F, Cattin F, Czorny A, Bonneville J (2002) Hypervascular intracisternal acoustic neuroma. J Neuroradiol 29(2):128-131

33. Guermazi A, Lafitte F, Miaux Y, Adem C, Bonneville J, Chiras J (2005) The dural tail sign-beyond meningioma. Clin Radiol 60(2):171-188

34. Sener RN (2003) Diffusion magnetic resonance imaging of solid vestibular schwannomas. J Comput Assist Tomogr 27(2):249-252

35. Singh K, Singh MP, Thukral C, Rao K, Singh K, Singh A (2015) Role of magnetic resonance imaging in evaluation of cerebellopontine angle schwannomas. Indian J Otolaryngol Head Neck Surg 67(1):21-27

36. Hari PS, Jyothi JA, Thatipamula M (2016) Study of posterior fossa tumors by high resolution MRI. J Evid Based Med Healthc 3(6):197-203

37. Roser F, Nakamura M, Dormiani M, Matthies C, Vorkapic P, Samii M (2005) Meningiomas of the cerebellopontine angle with extension into the internal auditory canal. J Neurosurg 102(1):17-23

38. Kapoor S, Kulkarni V (2018) Role of MRI in Evaluation of cerebello pontine angle tumour. J Adv Med Dent Scie Res 6(9):15-18

39. Haque S, Hossain A, Quddus M, Jahan M (2011) Role of MRI in the evaluation of acoustic schwannoma and its comparison to histopathological findings. Bangladesh Med Res Counc Bull 37(3):92-96

40. Springborg JB, Poulsgaard L, Thomsen J (2008) Nonvestibular schwannoma tumors in the cerebellopontine angle: a structured approach and management guidelines. Skull base 18(04):217-227

41. Farhan DA, Abdulsttar OA (2018) Role of diffusion-weighted image in differentiation between epidermoid cyst and other cerebellopontine angle masses. Med J Babylon 15(3):238-242

42. Pavlisa G, Rados M, Pazanin L, Padovan RS, Ozretic D, Pavlisa G (2008) Characteristics of typical and atypical meningiomas on ADC maps with respect to schwannomas. Clin Imaging 32(1):22-27

43. Mishra A, Thomas B, Kapilamoorthy T (2017) Susceptibility weighted imaging - a problem-solving tool in differentiation of cerebellopontine angle schwannomas and meningiomas. Neuroradiol J 30(3):253-258

44. Poptani H, Gupta RK, Jain VK, Roy R, Pandey R (1995) Cystic intracranial mass lesions: possible role of in vivo MR spectroscopy in its differential diagnosis. Magn Reson Imaging 13(7):1019-1029

45. Gujar SK, Maheshwari S, Björkman-Burtscher I, Sundgren PM (2005) Magnetic resonance spectroscopy. J Neuroophthalmol 25(3):217-226

46. Kothary N, Law M, Cha S, Zagzag D (2003) Conventional and perfusion MR imaging of parafalcine chondrosarcoma. Am J Neuroradiol 24(2):245-248

47. Müller U, Kubik-Huch RA, Ares C, Hug EB, Löw R, Valavanis A et al (2016) Is there a role for conventional MRI and MR diffusion-weighted imaging for distinction of skull base chordoma and chondrosarcoma? Acta Radiol 57(2): 225-232

48. Kumaran SP, Assis ZA, Viswamitra S, Ghosal N, Narayanam SK (2016) N-acetyl aspartate peak in extra-axial extraosseous chondrosarcoma of the brain on MRI: Unravelling a diagnostic dilemma. Neurol India 64(1):176

49. Aschenbach R, Basche S, Vogl TJ, Klisch J (2009) Diffusion-Weighted Imaging and ADC Mapping of Head-and-Neck Paragangliomas. Clin Neuroradiol 19(3):215-219

50. Maheshwari SR, Mukherji SK, Neelon B, Schiro S, Fatterpekar GM, Stone JA et al (2000) The choline/creatine ratio in five benign neoplasms: comparison with squamous cell carcinoma by use of in vitro MR spectroscopy. Am J Neuroradiol 21(10):1930-1935
51. Majoie C, Hulsmans F, Castelijns J, Sie L, Walter A, Valk (1999) Primary nervesheath tumours of the trigeminal nerve: clinical and MRI findings. Neuroradiology 41(2):100-108.

52. Wiggins R, Harnsberger H, Salzman K, Shelton C, Kertesz T, Glastonbury C (2006) The many faces of facial nerve schwannoma. Am J Neuroradiol 27(3): 694-699

\section{Publisher's Note}

Springer Nature remains neutral with regard to jurisdictional claims in published maps and institutional affiliations.

\section{Submit your manuscript to a SpringerOpen ${ }^{\circ}$ journal and benefit from:}

- Convenient online submission

- Rigorous peer review

- Open access: articles freely available online

- High visibility within the field

- Retaining the copyright to your article

Submit your next manuscript at $\boldsymbol{\nabla}$ springeropen.com 